\title{
Injection of $\mathrm{CO}_{2} / \mathrm{N}_{2}$ gaseous mixtures into gas hydrates to contemporary perform $\mathrm{CH}_{4}$ recovery and $\mathrm{CO}_{2}$ storage.
}

\author{
Mirko Filipponi ${ }^{1}$, Alberto Maria Gambelli ${ }^{1, *}$, Yan $\mathrm{Li}^{2}$, Andrea Presciutti ${ }^{3}$, Beatrice \\ Castellani ${ }^{1}$, Andrea Nicolini ${ }^{1}$, Federico Rossi ${ }^{1}$, Franco Cotana ${ }^{1}$ \\ ${ }^{1}$ University of Perugia, Engineering Department, Via G. Duranti 93, 06125, Perugia, Italy \\ ${ }^{2}$ Institute of Deep-Sea Science and Engineering, Chinese Academy of Science, Sanya 572000, China \\ ${ }^{3}$ Universitas Mercatorum, Piazza Mattei 10, 00186 Rome, Italy
}

\begin{abstract}
Carbon dioxide injection into natural gas hydrate reservoirs represents a promising opportunity to predispose a theoretically carbon neutral energy source. This technique allows to replace methane molecules with an equal number of carbon dioxide molecules and, consequently, to balance in advance emissions associated to methane utilization. While the direct $\mathrm{CH}_{4} / \mathrm{CO}_{2}$ replacement has been widely investigated, more data and scientific evidences are required to well define the feasibility of recovering methane by replacing it with $\mathrm{CO}_{2}$-based gaseous mixtures. In this sense, the most promising opportunity consists in flue-gas mixtures. In some cases, the presence of nitrogen was found capable to improve the overall efficiency, due to the direct competition between $\mathrm{CH}_{4}$ and $\mathrm{N}_{2}$ molecules to fill small cages characterizing hydrate structures. Moreover, these mixtures are extremely less-expensive than pure carbon dioxide. In this work, a binary $\mathrm{CO}_{2} / \mathrm{N}_{2}(50 / 50 \mathrm{vol} \%)$ gaseous mixture was used to recover methane contained into hydrate structures. Experiments were carried out in a smallscale experimental apparatus, designed to simulate a natural gas hydrate reservoir and to intervene on it with replacement techniques. Composition of gaseous mixtures present into hydrates and in the gaseous phase present immediately above, where defined via gas-chromatographic analyses. Finally, results were compared with data currently present in literature, in order to validate their consistency.
\end{abstract}

Keywords: natural gas hydrates; $\mathrm{CO}_{2}$ capture; flue-gas; methane replacement.

\section{Introduction}

Natural gas hydrates (NGH) are white and ice-like crystalline compounds, mainly formed from methane molecules trapped inside solid cages composed by water molecules [1]. To be stable, these compounds need of relatively high pressures and lower temperatures. For this reason, hydrates mainly occur in terrestrial permafrost and deep oceans sediments [2]. Gas hydrates consist of non-stoichiometric cage-type crystalline 
compounds and assume high storage density: one cubic meter of NGH can contain up to $164 \mathrm{~m}^{3}$ of methane [3]. In the mid-1960, these compounds started being considered a potential new energy source, due to their high content in methane and their diffusion worldwide [4]. For the first time in 1980, the possibility of recovering methane by replacing it with carbon dioxide, was explored [3]. Despite energy production, such strategy works on $\mathrm{CO}_{2}$ sequestration in solid form and allows to a potentially carbon neutral energy source [5, 6]. The exchange ratio between methane and carbon dioxide molecules, into already existing water cages, is theoretically equal to one; consequently, the amount of $\mathrm{CO}_{2}$ released in atmosphere during combustion of methane recovered, would be equal to the amount previously captured from the atmosphere and permanently stored [7]. Both gases form the cubic sI hydrate structure, thus any transition occurs during the exchange process. The feasibility of such process depends on the milder thermodynamic conditions required by $\mathrm{CO}_{2}$ molecules to form hydrates, if compared with methane molecules, which is related to the lower enthalpy of $\mathrm{CO}_{2}$ hydrate formation $(-57.98 \mathrm{~kJ} / \mathrm{mol}$, while it is about -54.49 $\mathrm{kJ} / \mathrm{mol}$ for methane hydrate) [8]. Generally, the replacement process can be performed in two different ways. In the first case, $\mathrm{CO}_{2}$ hydrate formation occurs only after the initial $\mathrm{CH}_{4}$ hydrate dissociation. This method implies the dissolution of water cages and the following formation of hydrates containing carbon dioxide $[9,10]$. The second way consist of a direct exchange into already existing crystalline structures [11]. This latter possibility is clearly preferred, because the sediment does not undergo alterations and the risk of hydrogeological instability remains low [12].

However, the direct employment of pure carbon dioxide in replacement processes presents some critical challenges, which currently reduce drastically its competitivity. The exchange between two gaseous compounds in hydrate structures, is related to the existence of a thermodynamic region in which the formation of the first specie is possible, while it is unfeasible for the second specie, which can only remain and/or return in/to the gaseous phase. Considering these two gases, the thermodynamic region as soon described is particularly narrow, especially for relatively low pressure values. It means that, during the process, the re-formation of methane hydrates may occur, with a consequent drop in effectiveness. Moreover, the production of pure carbon dioxide leads to further costs and makes the process even less competitive [13].

Both problems can be addressed with the use of gaseous mixtures containing carbon dioxide. Among them, the most accredited solution is flue-gas. When pure carbon dioxide is used, the exchange is possible only in $5^{12} 6^{2}$ middle size cavities, while it is not feasible in $5^{12}$ small cavities, which can contain also molecules having size similar or smaller than that of methane molecule. Consequently, methane recovery cannot exceed $75 \%$. Due to their relatively low dimension, nitrogen molecules are able to replace methane in small cages and higher efficiencies can be achieved.

On the other hand, nitrogen requires more severe thermodynamic conditions to form hydrates the use of flue-gas mixture is limited by concentration of $\mathrm{CO}_{2}$ in the gaseous mixture and the presence of feasible pressures and temperatures [14].

This work analyses the replacement of methane with a flue-gas mixture containing an equal volume of nitrogen and carbon dioxide. The binary mixture was initially used for direct hydrate production and formation values were compared with how present in literature $[15,16]$. Later, methane hydrates were formed and the gaseous phase was replaced with flue-gas, with the aim to evaluate the amount of methane recovery and carbon dioxide stored.

\section{Materials and Methods}




\subsection{Experimental apparatus}

Experiments described in this work were carried out in a small-scale experimental apparatus, designed to simulate an offshore hydrate reservoir. Here a brief description of the whole apparatus is provided; however, more detailed information is available elsewhere in literature $[17,18]$. The core consists of a cylindrical-volume unstirred reactor, entirely made with $316 \mathrm{SS}$. The top and the bottom are closed with two flanges, equipped with apposite channels used for gas injection and to host sensors. Gas can be injected from the top and from the bottom; in the present work, the injection from the bottom was selected. A digital manometer, model MAN-SD and four Type K thermocouples were used to measure respectively pressure and temperature. The reactor is immersed in a thermostatic bath, filled with water and glycol. The bath is equipped with a double copper coil, in which the refrigerant fluid is continuously circulated with a chiller, model GC-LT, to control the internal temperature. Finally, a further channel was thought for gas ejection. It allows to directly eject the whole gaseous phase present inside the reactor and is also gifted with a pressure reducer and a porous septum to take samples.

Figure 1 shows a scheme of the experimental apparatus (at left) and a picture of the ejection channel, as soon described.

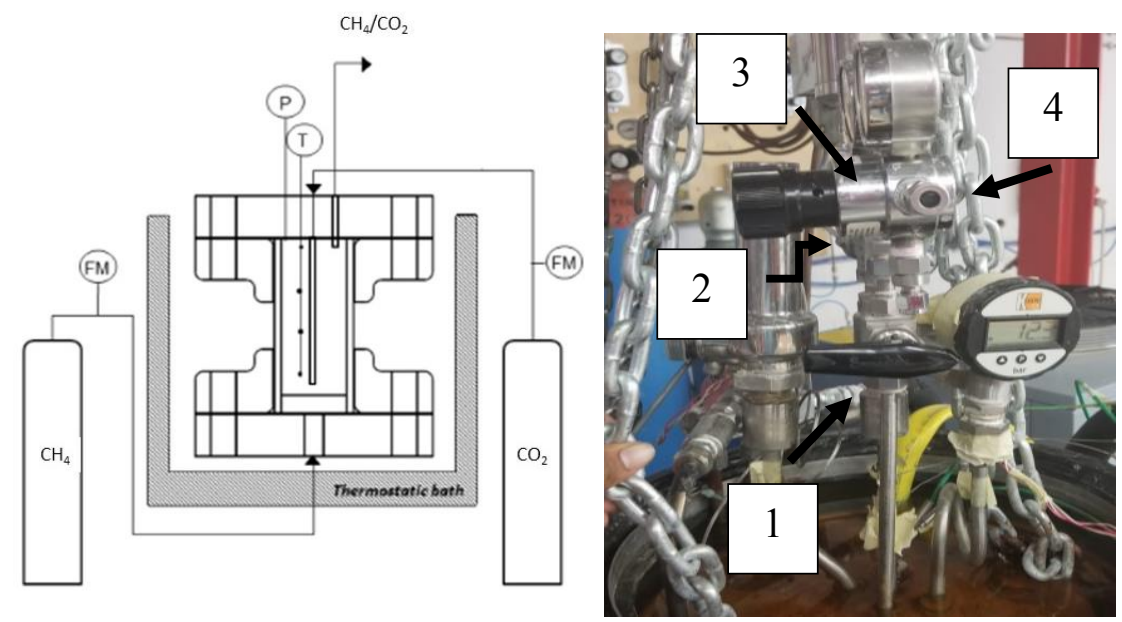

Fig. 1. Scheme of the lab-scale experimental apparatus (at left) and picture of the ejection channel (at right; in the figure: main ejection valve (1); secondary ejection valve (2); pressure reducer (3); porous septum (4)).

The ejection channel is equipped with two valves: the first is positioned between the experimental volume and the pressure reducer; conversely, the second valve is placed above the pressure reducer and directly communicates with the external. When the only main valve is opened, the pressure reducer can be used to move part of the gaseous mixtures in a secondary little volume where, thanks to the presence of the porous septum it can be easily taken for further analyses.

\subsection{Materials}

The internal volume was filled with porous sand $\left(744 \mathrm{~cm}^{3}\right)$ and pure demineralized water $\left(236 \mathrm{~cm}^{3}\right)$. Sand consists of quartz porous spheres, having diameter equal to $500 \mu \mathrm{m}$; its porosity was evaluated with a porosimeter, model Thermo Scientific Pascal 140. Also space present between grains was considered, because it exercises the same role of intrapores space. The overall porosity is equal to 34\%. Experiments were performed with 
methane and a binary gaseous mixture containing nitrogen and carbon dioxide. Both gases are UHP (ultra-high purity degree): about methane, the guaranteed concentration is at least $99.97 \%$, while the flue-gas concentration is $50 \mathrm{CO}_{2} / 50 \mathrm{~N}_{2}$, with an uncertainty of $\pm 0.01 \%$.

\subsection{Methods}

Before each test, an initial gas stream was provided through the reactor for air removal (if present). At the same time, temperature was lowered and brought to $1-3{ }^{\circ} \mathrm{C}$. Two types of experiments were made: in the first, hydrates were directly formed with flue-gas and methane was not involved in the process. This experiment was made to detect thermodynamic conditions feasible for the process in presence of such mixture and also to compare experimental values with what present in literature. The second typology of experiments comprises two phases: firstly, methane hydrates were formed; then the gaseous methane was removed and replaced with flue-gas, in order to favour the exchange between these two gases in previously formed water cages.

In both cases, gas injection was slow and gradual. Once the target pressure was reached, the reactor was closed and the system started operating in batch conditions. Hydrates formation is exothermic and the formation of first nuclei, at the beginning of the process, may generate a peak in temperature (it explains why, in some tests, the initial temperature is higher than $1-3^{\circ} \mathrm{C}$ ).

When hydrates were directly formed with flue-gas, the test was considered finished as soon pressure stabilized and remained constant at the current temperature. The same assumption was made for methane hydrates; however, once they were formed, the replacement process started. The ejection valve was opened and the gaseous phase was entirely removed from the reactor. As soon as it was completely ejected, the flue-gas mixture was inserted, at pressures close to 38 bar. This phase was extremely fast, less than 40 seconds were spent to complete it, in order to maintain the quantity of hydrates, dissociated during this phase, negligible. Then, the replacement phase begun. Here, any variation in pressure can be considered to evaluate the process with accuracy, because fluegas hydrates formation can occur together with methane hydrates dissociation and the contemporary occurrence of two processes, having an opposite effect on pressure, makes this latter parameter useless. By considering previous works focused on replacement strategies, the system was kept free to operate for a time period enough extended to ensure the completion of the whole process $[19,20]$. The effectiveness of the replacement was defined via gas-chromatographic analysis, which allowed to establish the percentage of methane recovered (as a function of the whole amount present into hydrates) and the amount of carbon dioxide captured (as a function of the initial quantity injected inside the reactor).

Despite pressure and temperature, which were directly measured, experiments were described by evaluating further relevant parameters. Moles of hydrate formed were calculated according to Equation 1:

$$
n_{H Y D}=\frac{V_{P O R E}\left(P_{i} Z_{f}-P_{f} Z_{i}\right)}{z_{f}\left(R T-\frac{P_{f}}{\rho_{H Y D}}\right)}
$$

Where $V_{\text {PORE }}$ is the volume available for hydrates formation, inside and between sand pores; "R" and "Z" describe respectively the gas constant and the compressibility factor; " $\rho_{\text {HYD }}$ " is the ideal molar density, calculated considering $100 \%$ volume occupancy, according to Aregba [21]. Finally, subscripts "i" and "f" indicate the beginning and the ending of the specific period during which $\mathrm{n}_{\mathrm{HYD}}$ was calculated.

To correctly evaluate the quantities of gas injected in the reactor, stored into hydrates and recovered during replacement, moles of water involved into hydrates and, 
consequently, the free volume present inside the reactor at every step, were evaluated. To do this, the hydration number, which indicates the ratio between water and guest molecules involved into hydrates, was considered equal to 6 .

\section{Results and Discussion}

The experimental section consists of three experiments: the first described $\mathrm{CO}_{2} / \mathrm{N}_{2}$ hydrates formation, while the others characterize the replacement of methane with the same flue-gas mixture used in the first test.

Test 1, where only flue-gas hydrates formation was testes, is described in Table 1 and in figures 2 and 3. Finally, Figure 4, shows equilibrium for $\mathrm{CO}_{2} / \mathrm{N}_{2}$ hydrates starting from different initial concentrations.

Table 1. Main parameters describing Test 1, consisting of flue-gas hydrates formation.

\begin{tabular}{|c|c|c|}
\hline Parameter & Value & Unit \\
\hline $\mathrm{P}_{\mathrm{i}}$ & 38.02 & bar \\
\hline $\mathrm{T}_{\mathrm{i}}$ & 6.3 & ${ }^{\circ} \mathrm{C}$ \\
\hline $\mathrm{P}_{\mathrm{f}}$ & 22.68 & bar \\
\hline $\mathrm{T}_{\mathrm{f}}$ & 2.1 & ${ }^{\circ} \mathrm{C}$ \\
\hline $\mathrm{n}_{\mathrm{N} J}$ & 0.461 & $\mathrm{~mol}$ \\
\hline $\mathrm{n}_{\mathrm{CO} 2 \mathrm{DISS}}$ & 0.29 & $\mathrm{~mol}$ \\
\hline $\mathrm{n}_{\mathrm{HYD}}$ & 0.216 & $\mathrm{~mol}$ \\
\hline $\mathrm{n}_{\mathrm{GAS}}$ & 0.245 & $\mathrm{~mol}$ \\
\hline$\%_{\mathrm{CO}}$ & 24.683 & $\mathrm{Vol} \%$ \\
\hline$\%_{\mathrm{N}}$ & 75.317 & $\mathrm{Vol} \%$ \\
\hline $\mathrm{n}_{\mathrm{CO} 2 \mathrm{HYD}}$ & 0.169 & $\mathrm{~mol}$ \\
\hline $\mathrm{n}_{\mathrm{N} 2 \mathrm{HYD}}$ & 0.046 & $\mathrm{~mol}$ \\
\hline $\mathrm{CO}_{2}$ captured & 88.1 & $\%$ \\
\hline & & \\
\hline
\end{tabular}

Table 1 shows pressure and temperature at the beginning and the ending of hydrates formation, the overall amount of flue-gas injected ( $\mathrm{n}_{\mathrm{INJ}}$ ), the quantity of $\mathrm{CO}_{2}$ dissolved in water ( $n_{\text {CO2DISS }}$ ), the amount of hydrates produced $\left(\mathrm{n}_{\mathrm{HYD}}\right)$, moles remained in the gaseous phase and their composition. Finally, $\mathrm{CO}_{2}$ captured is the ratio between carbon dioxide stored and the overall quantity injected inside. The first term includes moles involved in hydrates formation and moles dissolved in water, while the second is the sum of the gaseous and the dissolved in water quantities. 


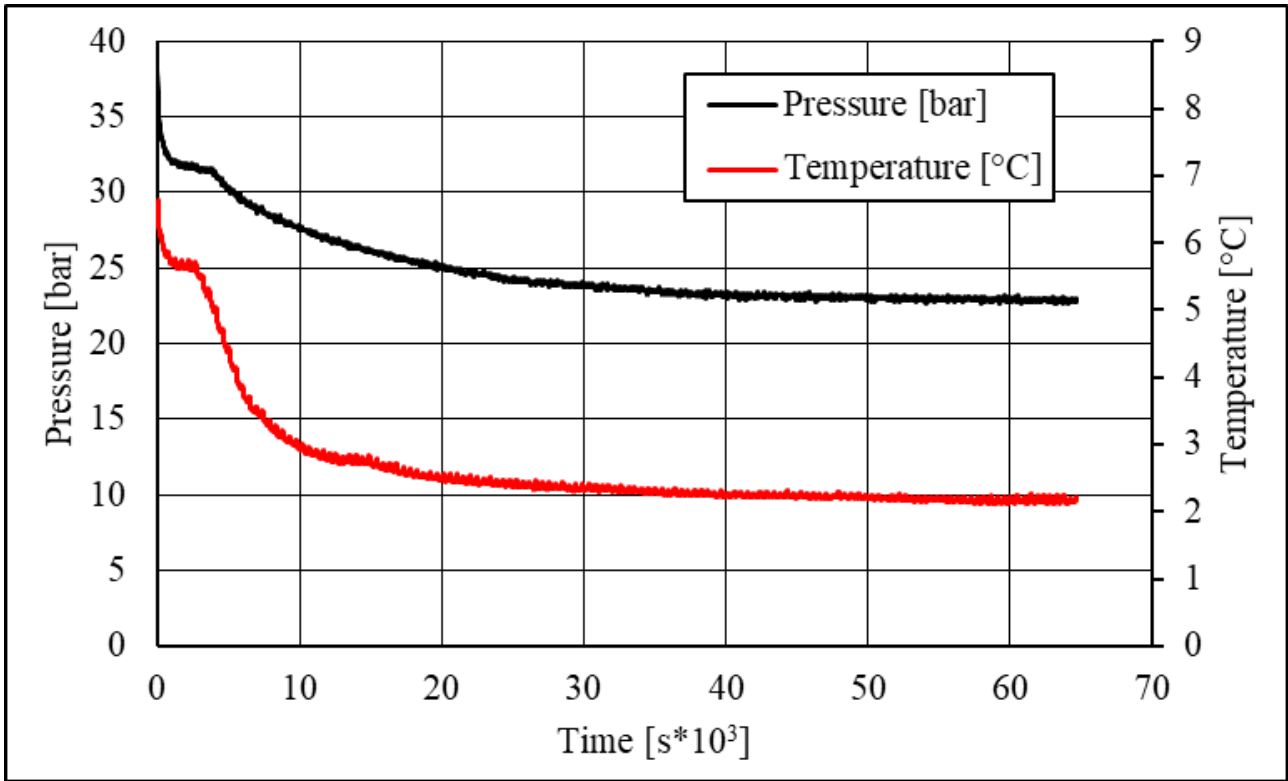

Fig. 2. Pressure and temperature trend over time, measured in Test 2.

Hydrates formation was intensive and led to a drop in pressure close to 16 bar. In particular, hydrates mainly formed during the first $20^{*} 10^{3}$ seconds; however, the pressure required more than $60 * 10^{3}$ seconds to stabilize. After the initial peak, the decrease in temperature was not linear and two little variations were observed. These peaks were related to an acceleration of hydrates formation.

As expected, the process mainly involved carbon dioxide: the mixture remained above hydrates, once the process finished, contained $24.683 \%$ of $\mathrm{CO}_{2}$ and $75.317 \%$ of $\mathrm{N}_{2}$. It means that the concentration of carbon dioxide in the gaseous mixture has halved, compared to the initial concentration.

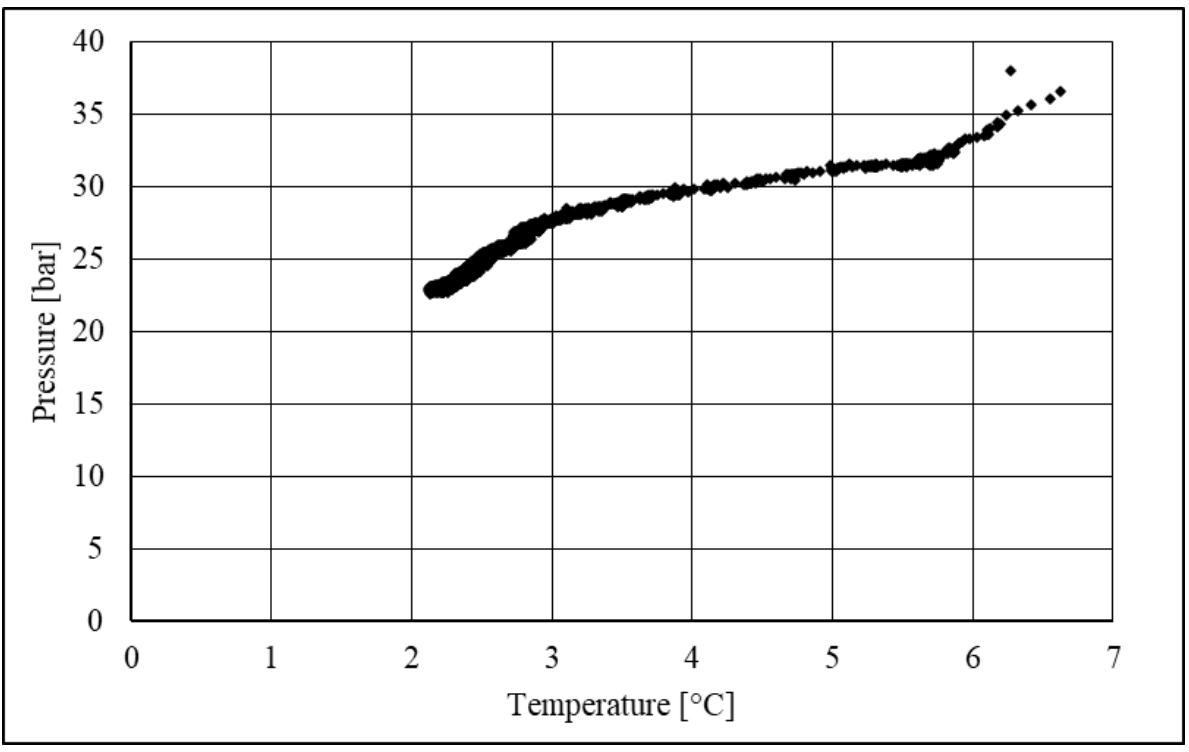

Fig. 3. Pressure and temperature trend over time, measured in Test 1. 


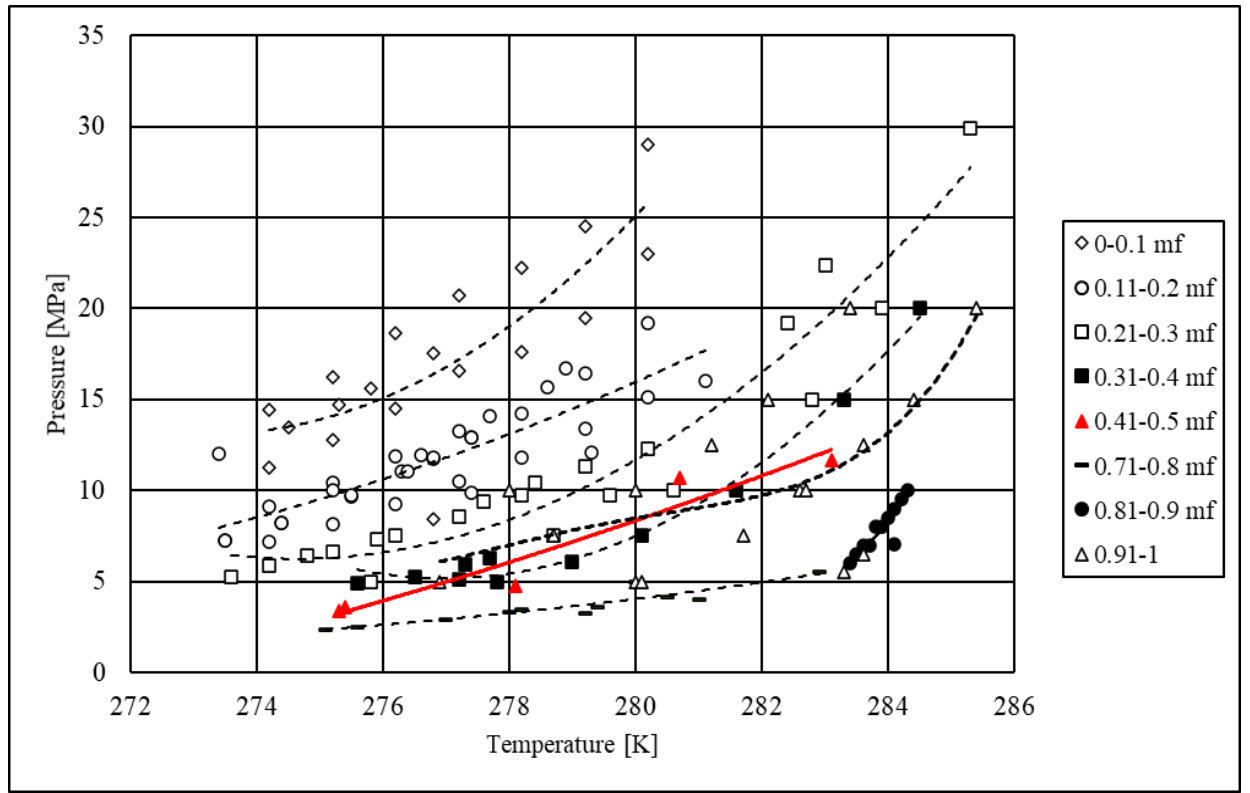

Fig. 4. Pressure-temperature diagram, describing the phase equilibrium for binary $\mathrm{CO}_{2} / \mathrm{N}_{2}$ mixtures, shown in function of the initial $\mathrm{CO}_{2}$ concentration, which was expressed in molar fraction (mf) $[22-$ 31].

In this latter diagram, equilibrium conditions for $\mathrm{CO}_{2} / \mathrm{N}_{2}$ hydrates were reported for different initial concentrations. All curves were shown in black, except for the equilibrium line obtained for concentrations close to what used in this work. As expected, the mildest thermodynamic conditions were obtained for mixtures mainly containing carbon dioxide. However, it was observed that, also the presence of very low concentrations of carbon dioxide are able to drastically reduce pressure required for hydrates formation (if compared with pure nitrogen).

The experimental curve, showed in Figure 3, is below the red one, showed in Figure 4 and two reason can motivate such difference. Firstly, the red line also includes mixture with lower $\mathrm{CO}_{2}$ concentrations than $0.5 \mathrm{mf}$. In addition, experiments were carried out in presence of a porous medium made with pure quartz, which does not chemically affect the process, but allows to increase the surface/volume ratio and the number of gas-liquid interfaces present inside the reactor, thus improving the formation process.

Several researchers asserted that reactors used to study hydrates, because of their little size, usually affect the process and, and results may be slightly different in function of the specific reactor used to produce them [32]. As a consequence of it, this preliminary experiment was realized to characterize hydrate formation with a binary $\mathrm{CO}_{2} / \mathrm{N}_{2}(50 / 50$ vol\%) gaseous mixture in the same reactor used to investigate the replacement of methane.

The following table describes Test 2 and Test 3, where the replacement of methane with flue-gas was directly tested.

Table 2. Main parameters describing Test 2 and Test 3, where methane contained into hydrates was replaced with flue-gas.

\begin{tabular}{|c|c|c|}
\hline Parameters & Test 2 & Test 3 \\
\hline \multicolumn{3}{|c|}{ Methane hydrates formation } \\
\hline Pi [bar] & 53.35 & 50.57 \\
\hline $\operatorname{Ti}\left[{ }^{\circ} \mathrm{C}\right]$ & 9.6 & 1.6 \\
\hline
\end{tabular}




\begin{tabular}{|c|c|c|}
\hline $\mathrm{n}_{\mathrm{CH} 4 \mathrm{inj}}[\mathrm{mol}]$ & 0.599 & 0.617 \\
\hline $\operatorname{Pf}[$ bar $]$ & 24.46 & 27.56 \\
\hline $\operatorname{Tf}\left[{ }^{\circ} \mathrm{C}\right]$ & 0.9 & 1.8 \\
\hline nCH4HYD [mol] & 0.389 & 0.333 \\
\hline $\mathrm{H}_{2 \mathrm{Oin}}$ hyd [1] & 0.042 & 0.036 \\
\hline $\mathrm{V}_{\text {HYD }}[1]$ & 0.042 & 0.045 \\
\hline VFREe [1] & 0.224 & 0.226 \\
\hline \multicolumn{3}{|c|}{ Flue-gas injection } \\
\hline $\mathrm{P}_{\mathrm{INJ}}[\mathrm{bar}]$ & 37.19 & 36.35 \\
\hline $\mathrm{T}_{\text {INJ }}\left[{ }^{\circ} \mathrm{C}\right]$ & -0.3 & 0.2 \\
\hline $\mathrm{n}_{\text {INJ }}[\mathrm{mol}]$ & 0.428 & 0.419 \\
\hline $\mathrm{n}_{\mathrm{CO} 2}[\mathrm{~mol}]$ & 0.214 & 0.21 \\
\hline $\mathrm{n}_{\mathrm{N} 2}[\mathrm{~mol}]$ & 0.214 & 0.21 \\
\hline \multicolumn{3}{|c|}{ Replacement } \\
\hline $\mathrm{P}_{\mathrm{R}}[\mathrm{bar}]$ & 33.05 & 34.49 \\
\hline $\mathrm{T}_{\mathrm{R}}\left[{ }^{\circ} \mathrm{C}\right]$ & 1.1 & 1.8 \\
\hline$\Delta \mathrm{nHYD}[\mathrm{mol}]$ & 0.071 & 0.033 \\
\hline $\mathrm{V}_{\mathrm{HYD}}(\Delta \mathrm{n})[1]$ & 0.01 & 0.005 \\
\hline $\mathrm{H}_{2 \text { Oinhyd [1] }}$ & 0.008 & 0.004 \\
\hline $\mathrm{V}_{\mathrm{GAS}}[1]$ & 0.223 & 0.225 \\
\hline $\mathrm{n}_{\mathrm{GAS}}[\mathrm{mol}]$ & 0.323 & 0.332 \\
\hline $\mathrm{CO}_{2}[\mathrm{Vol} \%]$ & 18.3 & 20.71 \\
\hline $\mathrm{N}_{2}[\mathrm{Vol} \%]$ & 50.13 & 53.85 \\
\hline $\mathrm{CH}_{4}[\mathrm{Vol} \%]$ & 31.57 & 25.44 \\
\hline $\mathrm{nCO}_{2}[\mathrm{~mol}]$ & 0.059 & 0.068 \\
\hline $\mathrm{nN}_{2}[\mathrm{~mol}]$ & 0.162 & 0.179 \\
\hline $\mathrm{nCH}_{4}[\mathrm{~mol}]$ & 0.102 & 0.085 \\
\hline $\mathrm{CO}_{2 \mathrm{CAP}}[\%]$ & 72.43 & 67.62 \\
\hline $\mathrm{N}_{2 \mathrm{CAP}}[\%]$ & 24.3 & 14.76 \\
\hline $\mathrm{CH}_{4 \mathrm{REC}}[\%]$ & 26.22 & 25.53 \\
\hline
\end{tabular}

The table is divided in three sections, respectively describing methane hydrates formation, the removal of methane, which was not involved in the process, and the injection of flue-gas and, finally, the replacement process. The first section was described with the initial and final pressure and temperature values, moles of methane injected, moles of hydrates formed, water involved into hydrates, volume occupied by hydrates and the remaining volume containing the gaseous phase.

The second step was characterized with pressure and temperature measured as soon as the injection was finished, moles of flue gas injected and the specific amount of nitrogen and carbon dioxide. The last phase was defined with the final pressure and temperature, measured at the end of the whole process, the variation in the overall quantity of hydrates present inside the reactor, occurred during this phase, water and volume associated to this variation, volume interested by the gaseous phase and the concentration of each compound in the gaseous phase, with the associated number of moles. Finally, carbon dioxide and nitrogen captured into hydrates were calculated with the following equation:

$$
n_{C A P}=\frac{n_{I N J}-n_{G A S}}{n_{I N J}} * 100
$$

Conversely, methane recovered was defined as the ratio between moles present in the gaseous phase at the end of the test and moles initially trapped into hydrates, expressed as percentage.

Both tests led to similar results in terms of methane hydrate formation: in the first case, 0.389 moles of hydrate were formed, while 0.333 moles in the second experiment. The process started at initial pressures close to 50 bar and reached $24-28$ bar as final values. 
The main difference was observed in temperature trend: Test 2 showed an immediate peak in temperature and the first values measured were close to $10{ }^{\circ} \mathrm{C}$. Conversely, in Test 3 hydrates formation did not occur immediately and temperature initially remained in the range externally established with the chiller. Once moles of hydrates formed were evaluated, also water involved in the process and volume occupied by hydrates were measured, in order to evaluate with accuracy the free volume feasible for flue-gas injection.

This latter compound was injected at pressures about $36-37$ bar, or higher if compared with Pf values. It means that methane replacement into hydrates was not favoured by thermodynamic conditions, as commonly occurs when pure carbon dioxide is used, but it was only based on the higher tendency of flue-gas (than methane) to be involved into hydrates at the same thermodynamic condition. Considering the high concentration of nitrogen, the equilibrium conditions for the present mixture are more severe than that for methane hydrates and any drop in pressure or increase in temperature can be performed to enhance the process.

Knowing the volume available to host flue-gas and the composition of the mixture, the exact number of carbon dioxide and nitrogen moles inserted into the reactor, was defined. The replacement process did not cause any significant variation in pressure, neither remarkable peaks in temperature. In Test 2, the pressure moved from 37.19 bar to 33.05 bar, while in Test 3, from 36.35 bar, it reached 34.49 bar. This little difference did not provide enough information to define the effectiveness of replacement, which was evaluated with the auxilium of gas-chromatographic analyses. However, this little decrease in pressure proved that, in any case, the amount of flue-gas involved in the process was higher than the methane recovered. The ending of the replacement phase was established as a function of time, according to previous works, where time required to complete the process was defined [33]. Here, a time period significantly higher than this latter one, was considered, to ensure the completion of the whole process. That solution was adopted due to the impossibility of considering pressure and temperature trend to define it.

As soon as the process finished, the gaseous phase present upon hydrates was analysed and revealed the following composition: $18.3-20.71 \% \mathrm{CO}_{2} ; 50.13-53.85 \% \mathrm{~N}_{2} ; 25.44-$ $31.57 \% \mathrm{CH}_{4}$. Even if the thermodynamic conditions remained feasible for methane hydrate stability, part of methane was released from hydrates and was found in the gaseous phase. Between the two compounds present in the flue-gas mixture, carbon dioxide was preferentially involved into hydrates and showed a lower concentration in the gaseous phase. In Test 2, the gaseous phase above methane hydrates, initially contained 0.214 moles of both compound; conversely, when the process finished, 0.059 moles of $\mathrm{CO}_{2}$ and 0.162 moles of $\mathrm{N}_{2}$ were found, confirming that $\mathrm{CO}_{2}$ was mainly involved in the process and proving the participation of nitrogen in the replacement. Similar conclusions follow results belonging to Test 3 , where the final gaseous phase contained 0.068 moles of $\mathrm{CO}_{2}$ and 0.179 moles of $\mathrm{N}_{2}$.

The last three parameters were used to clearly define the effectiveness of methane replacement with this specific flue-gas mixture. More than two third of carbon dioxide inserted in the reactor was trapped into water structures, proving a high capture efficiency, if considering its relatively low concentration in the initial mixture. The percentage of nitrogen was clearly lower and ranged from $14.76 \%$ to $24.3 \%$. If pure nitrogen had been used there would have been no methane recovery, neither nitrogen storage. In a binary gaseous mixture, nitrogen participated to the process and contributed to increase methane recovery. Finally, the percentage of methane recovered was unsatisfactory (about 25.53 $26.22 \%$ ) and must be significantly increased to make the process attractive. Two main reasons can be attributed to these results: the low content in carbon dioxide of the mixture used to carry out the replacement and low diffusion of flue-gas into the methane hydrated deposit. The initial phase was extremely intensive and methane hydrates formation 
interested the whole internal reactor, leaving too little free space for flue-gas diffusion. Due to this latter challenge, part of methane hydrates present inside the reactor, remained far from the replacement zone and the percentage of methane recovered remained consequently low.

Finally, temperature and pressure trend over time was shown for both experiments (figures $3-6$ ).

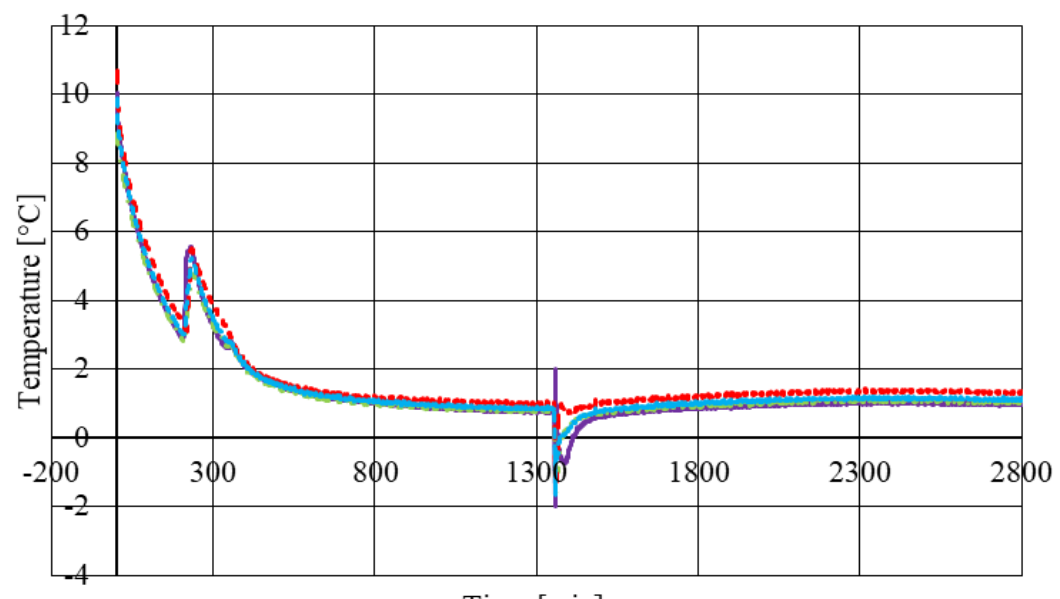

Time $[\mathrm{min}]$

$\mathrm{T} 16\left[{ }^{\circ} \mathrm{C}\right] \quad--\mathrm{T} 11\left[{ }^{\circ} \mathrm{C}\right] \quad--\mathrm{T} 07\left[{ }^{\circ} \mathrm{C}\right] \quad----\mathrm{T} 02\left[{ }^{\circ} \mathrm{C}\right]$

Fig. 5. Temperature trend over time measure in Test 2.

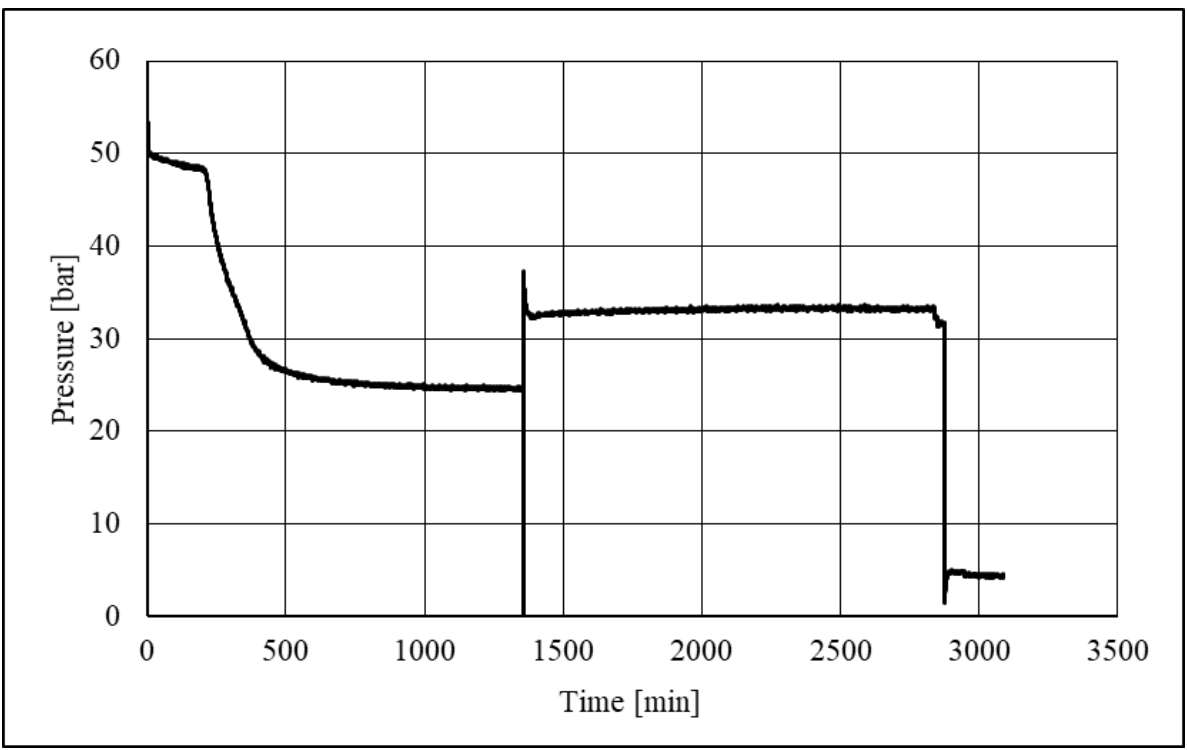

Fig. 6. Pressure trend over time measure in Test 2. 


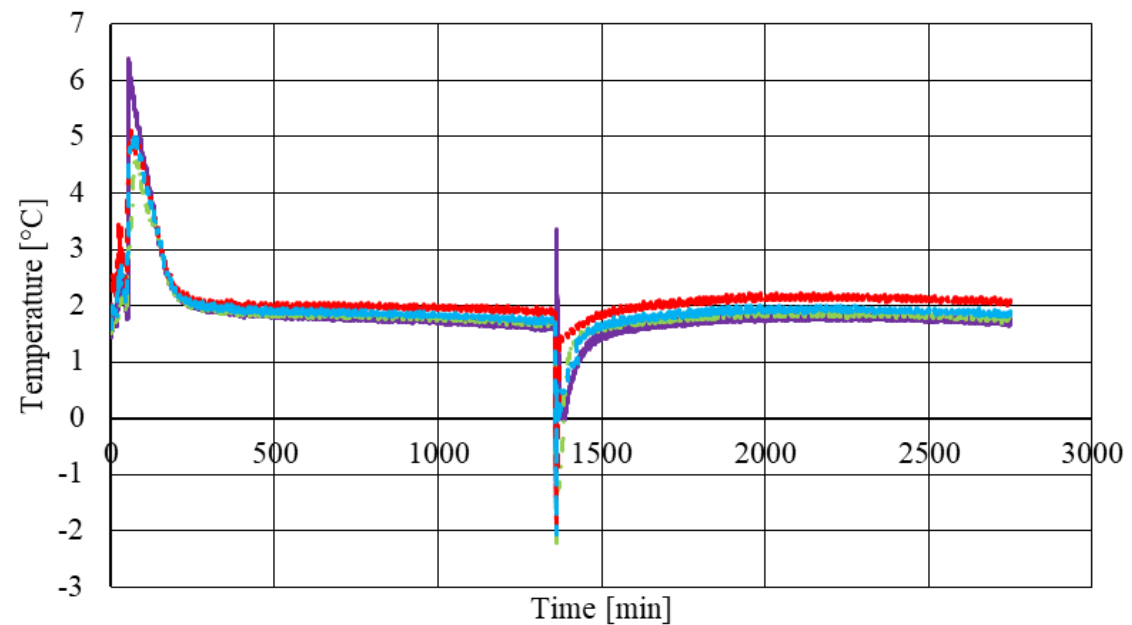

Time $[\mathrm{min}]$

$-\mathrm{T} 16\left[{ }^{\circ} \mathrm{C}\right] \quad-\cdot \mathrm{T} 11\left[{ }^{\circ} \mathrm{C}\right]---\mathrm{T} 07\left[{ }^{\circ} \mathrm{C}\right] \quad--\mathrm{T} 02\left[{ }^{\circ} \mathrm{C}\right]$

Fig. 7. Temperature trend over time measure in Test 3.

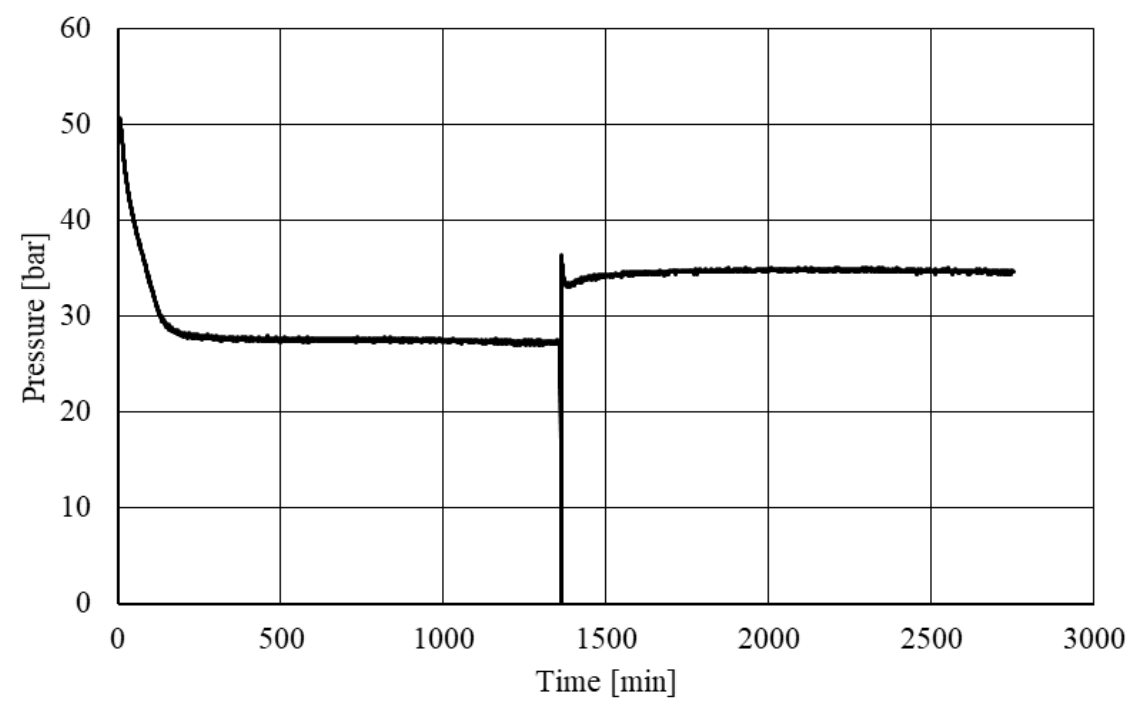

Fig. 8. Temperature trend over time measure in Test 3.

These diagrams graphically confirmed the previous description, based on results shown in Table 1. Methane hydrates formation was massive in both cases and a relevant temperature peak was consequently found: in Test 2 it occurred immediately, while in Test 3 it was measured after a certain time period. It mainly deepened from the stochastic nature of the reaction, which might not start immediately, even if the thermodynamic conditions are completely feasible. In addition, in Test 2 , a secondary peak was observed, proving the formation of further hydrates nuclei in the reactor. Gaseous methane removal and flue-gas injection were performed very quickly and the variation in temperature related to them consists of an almost vertical treat. However, some thermocouples measured an increase in temperature, while the other revealed a local decrease. Firstly, methane was ejected and the gas expansion led to a decrease in pressure. However, gas expanded only in regions left free from hydrates and temperature decreased only in those regions. For the opposite reason, the 
subsequent flue-gas injection brought to an increase in temperature in the same regions, which was less marked than the previous drop. The presence of free water and feasible thermodynamic conditions, led to an immediate formation of $\mathrm{CO}_{2}$ hydrates (independently from the replacement process) which caused a remarkable increase in temperature. Finally, any significant variation was observed during replacement.

Pressure diagrams revealed how methane hydrates mainly formed during the first hours. In Test 2, the process accelerated immediately after the second temperature peak, while in Test 3 it assumed a constant gradient. Once hydrate formation was completed, pressure remained constant, until the second phase, where it decreased to the atmospheric value, due the removal of the whole gaseous phase present inside the reactor; then it increased again and reached $P_{R}$. After an initial drop, mainly due to the ex-novo formation of carbon dioxide hydrates, pressure remained almost constant, proving that the leading process was gas exchange into already existing water cages, which did not cause relevant variation in pressure neither in temperature.

\section{Conclusions}

This work deals with methane replacement, into gas hydrates, with a binary flue-gas mixture, equally divided in carbon dioxide and nitrogen. Experiments were carried out in a small-scale experimental apparatus, appositely designed to simulate marine hydrates reservoirs. A first test consisted of direct formation of hydrates with flue-gas, in order to define the conditions required for their formation in the present reactor. Values produced where then compared with equilibrium values present in literature. The second part of this article, describes methane replacement with flue-gas. The replacement was performed by removing all gaseous methane and replacing it with flue-gas, as soon as the methane hydrates formation was completed. Both tests produced similar results: gas exchange, into previously formed water cages, occurred and was more abundant than ex-novo hydrates formation. As expected, carbon dioxide was mainly involved in the process $(67-73 \%$ of $\mathrm{CO}_{2}$ was captured and stored in form of hydrate); in addition, a significant percentage of nitrogen participated to the process, about $14-24 \%$, and provided a relevant contribution in terms of methane recovery. Finally, the percentage of methane recovered was low: it remained below $26 \%$ due to the low initial concentration of carbon dioxide in the replacing mixture and to difficulties addressed for flue-gas diffusion through the conglomerate of methane hydrates.

Future works will be focused on involving different flue-gas mixtures, with different initial concentrations; moreover, different strategies will be applied to carry out the replacement process, in order to improve its efficiency.

We would like to thank Mr Vasile Belbe for the priceless contribution; his practical experience let us to intensify our experimental activity and to increase the accuracy of data produced in our laboratory.

\section{References}

1. A.M. Gambelli, B. Castellani, A. Nicolini, F. Rossi. Experimental study on natural gas hydrate exploitation: Optimization of methane recovery, carbon dioxide storage and deposit structure preservation. J. Petrol. Sci. Eng., 177 (2019) $594-601$.

2. T. Collett. Energy resource potential of natural gas hydrates. AAPG Bull, 86 (2002) 1971-92. 
3. E.D. Sloan, C.A. Koh. Clathrate hydrates of natural gases. third ed. Boca Raton, FL,USA: CRC Press; 2007.

4. F. Rossi, A.M. Gambelli. Thermodynamic phase equilibrium of single-guest hydrate and formation data of hydrate in presence of chemical additives: a review. Fluid Phase Equilib., 536 (2021) 112958.

5. K. Ohgaki, Y. Inoue. A proposal for gas-storage on the ocean-floor using gas hydrates. Kagaku Kogaku Ronbun, 17 (1991) 1053-5.

6. C. Cranganu. A method for producing natural gas from gas hydrate deposits. In: Proceedings of the AAPG annual convention; 2005.

7. A.M. Gambelli, M. Filipponi, F. Rossi. How methane release may affect carbon dioxide storage during replacement processes in natural gas hydrate reservoirs. J. Petrol. Sci. Eng., 205 (2021) 108895, https://doi.org/10.1016/j.petrol.2021.108895

8. N. Goel. In situ methane hydrate dissociation with carbon dioxide sequestration: current knowledge and issues. J. Petrol. Sci. Eng., 51 (2006) 169-84.

9. Y. Seo, S. Lee, J. Lee. Experimental verification of methane replacement in gas hydrates by carbon dioxide. Chem. Eng. Trans., 32 (2013) 163-8.

10. C. Deusner, N. Bigalke, E. Kossel, M. Haeckel. Methane production from gas hydrate deposits through injection of supercritical CO2. Energies, 5 (2012) 2112-40.

11. D.Y. Koh, H. Kang, D.O. Kim, J. Park, M. Cha, H. Lee. Recovery of methane from gas hydrates intercalated within natural sediments using $\mathrm{CO} 2$ and a $\mathrm{CO} 2 / \mathrm{N} 2$ gasmixture. ChemSusChem, 5 (2012) 1443-8.

12. A.M. Gambelli. Natural gas recovery from hydrate compounds using $\mathrm{CO} 2$ replacement strategies: experimental study on thermal stimulation. Energy Procedia, 148 (2018) 647-654.

13. D.K. Sharma, M. Filipponi, A. Di Schino, F. Rossi, M.J.Castaldi. Corrosion behaviour of high temperature fuel cells: Issues for materials selection. Metalurgija, 58 (2019) 347-351.

14. A.M. Gambelli, U. Tinivella, R. Giovannetti, B. Castellani, M. Giustiniani, A. Rossi, M. Zannotti, F. Rossi. Observation of the Main Parameters Influencing the Formation of Gas Hydrates. Energies, 14 (2021) 1803.

15. L. Li, J. Zhao, L. Zhang, S. Fan, Q. Li, W. Pang, X. Lu, L. Zheng, N. Wei. A novel fitted thermodynamic model for the capture of $\mathrm{CO} 2$ from flue gas by the hydrate method. Natural Gas Industry B, 6 (2019) 603 - 609.

16. L. Li, S. Fan, G. Yang, Q. Chen, J. Zhao, N. Wei, W. Meng, J. Fan, H. Yang. Continuous simulation of the separation process of $\mathrm{CO}_{2} / \mathrm{H}_{2}$ by forming hydrate. Chem. Eng. Sci.: X, 7 (2020) 100067.

17. A.M. Gambelli, B. Castellani, A. Nicolini, F. Rossi. Water Salinity as Potential Aid for Improving the Carbon Dioxide Replacement Process' Effectiveness in Natural Gas Hydrate Reservoirs. Processes, 8 (2020) 1298.

18. A.M. Gambelli. An experimental description of the double positive effect of $\mathrm{CO}_{2}$ injection in methane hydrate deposits in terms of climate change mitigation. Chem. Eng. Sci., 233 (2021) 116430.

19. B. Castellani, A.M. Gambelli, A. Nicolini, F. Rossi. Energy and Environmental Analysis of Membrane-Based $\mathrm{CH}_{4}-\mathrm{CO}_{2}$ Replacement Processes in Natural Gas Hydrates. Energies, 12 (2019) 850.

20. A.M. Gambelli, F. Rossi. Natural gas hydrates: Comparison between two different applications of thermal stimulation for performing $\mathrm{CO}_{2}$ replacement. Energy, 172 (2019) $423-434$. 
21. A.G. Aregba. Gas Hydrate-Properties, Formation and Benefits. Open Journal of Yangtze Gas and Oil, 2 (2017) 27-44. https://doi.org/10.4236/ojogas.2017.21003.

22. D. Sadeq, S. Iglauer, M. Lebedev, C. Smith, A. Barifcani. Experimental determination of hydrate phase equilibrium for different gas mixtures containing methane, carbon dioxide and nitrogen with motor current measurements. J. Nat. Gas Sci. Eng., 38 (2017) $59-73$.

23. S. Shicai, Z. Yong, L. Changling, L. Yufeng. Preliminary study on measurement technology for hydrate phase equilibrium. Fluid Phase Equilib., 403 (2015) $60-69$.

24. A. Jarrahian, A. Nakhaee. Hydrate-liquid-vapor equilibrium condition for $\mathrm{N}_{2}+\mathrm{CO}_{2}+$ $\mathrm{H}_{2} \mathrm{O}$ system: Measurement and modelling. Fuel, 237 (2019) $769-774$.

25. V. Belandria, A.H. Mohammadi, A. Eslamimanesh, D. Richon, M.F. Sànchez-Mora, L.A. Galicia-Luna. Phase equilibrium measurements for semi-clathrate hydrates of the $(\mathrm{CO} 2+\mathrm{N} 2+$ tetra-n-butylammonium bromide) aqueous solution systems: Part 2. Fluid Phase Equilib., 322-323 (2012) $102-112$.

26. S.M. Kim, J.D. Lee, H.J. Lee, E.K. Lee, Y. Kim. Gas hydrate formation method to capture the carbon dioxide for pre-combustion process in IGCC plant. Int. J. Hydrog. Energy, 36 (2011) 1115-1121.

27. S.C. Sun, C.L. Liu, Q.G. Meng. Hydrate phase equilibrium of binary guest-mixtures containing CO2 and N2 in various system. J. Chem. Thermodyn., 84 (2015) 1 - 6.

28. A.M. Gambelli, A. Presciutti, F. Rossi. Review on the characteristics and advantages related to the use of flue-gas as $\mathrm{CO}_{2} / \mathrm{N}_{2}$ mixture for gas hydrate production. Fluid Phase Equilib., 541 (2021) 113077, doi: https://doi.org/10.1016/j.fluid.2021.113077

29. X. Zang, L. Wan, D. Liang. Investigation of the hydrate formation process in fine sediments by a binary CO2/N2 gas mixture. Chin. J. Chem. Eng., 27 (2019) 2157 2163.

30. H. Bruusgaard, J.G. Beltràn, P. Servio. Solubility measurements for the $\mathrm{CH}_{4}+\mathrm{CO}_{2}+$ $\mathrm{H}_{2} \mathrm{O}$ system under hydrate-liquid-vapor equilibrium. Fluid Phase Equilib., 296 (2010) $106-109$.

31. I.B.A. Sfaxi, I. Durand, R. Lugo, A.H. Mohammadi, D. Richon. Hydrate phase equilibria of $\mathrm{CO} 2+\mathrm{N} 2+$ aqueous solution of THF, TBAB or TBAF system. Int. J. Greenh. Gas Con., 26 (2014) 185 - 192.

32. V. Sh. Shagapov, M.K. Khasanov, N.G. Musakaev, Ngoc Hai Duong. Theoretical research of the gas hydrate deposits development using the injection of carbon dioxide. Int. J. Heat Mass Transf., 107 (2017) 347 - 357.

33. A.M. Gambelli, F. Rossi. The use of sodium chloride as strategy for improving $\mathrm{CO}_{2} / \mathrm{CH}_{4}$ replacement in natural gas hydrates promoted with depressurization methods. Arab. J. Geosci., 13 (2020) 898. 